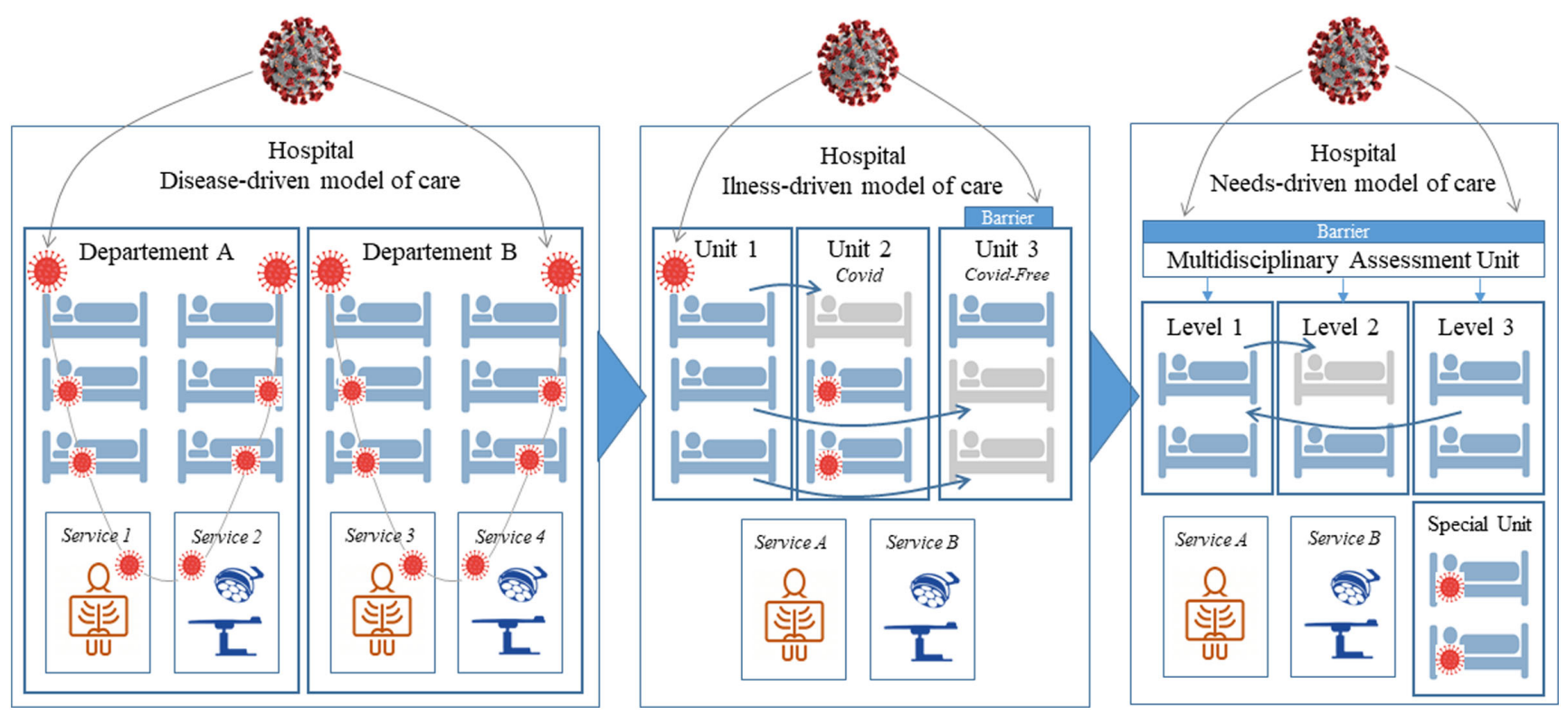

Fig. 1. Main transitions of the hospital model of care and response capacity to the spread of COVID-19.

health is achieved with cross cutting and coordinated interventions that go beyond medical treatment. The COVID-19 compelled us to run, and now we need to focus the coordinates in the right direction.

Author contributions. RG and ADB contributed to the literature review and to the final version of the manuscript. The first draft of the manuscript was written by RG.

Financial support. No financial support was provided relevant to this article.

Conflicts of interest. All authors report no conflicts of interest relevant to this article.

\section{References}

1. Bearman G, Pryor R, Albert H, et al. Novel coronavirus and hospital infection prevention: Preparing for the impromptu speech. Infect Control Hosp Epidemiol 2020;41:592-593.
2. Rosenbaum L. Facing COVID-19 in Italy-ethics, logistics, and therapeutics on the epidemic's front line. N Engl J Med 2020;382:1873-1875.

3. Understanding the process to develop a model of care. A practical guide on how to develop a model of care at the agency for clinical innovation, version 1.0. Agency For Clinical Innovation website. https://www.aci.health.nsw.gov.au/ __data/assets/pdf_file/0009/181935/HS13-034_Framework-DevelopMoC_D7. pdf. Published May 2013. Accessed February 19, 2020.

4. Liguori I, Russo G, Aran L, et al. Acute-care hospital at different levels of intensity: the role of geriatrician. Aging Clin Exp Res 2018;30:703-712.

5. Bardes CL. Defining "patient-centered medicine." $N$ Engl J Med 2012;366:782-783.

6. Bate P, Robert G. Experience-based design: from redesigning the system around the patient to codesigning services with the patient. Qual Saf Health Care 2006;15:307-310.

\title{
Saliva and its potential in coronavirus disease 2019 (COVID-19) cannot be ignored: A point of view
}

\author{
Sukhvinder Singh Oberoi BDS, MDS$^{1}$ (1), Shabina Sachdeva BDS, MDS², Shibani Grover BDS, MDS $^{3}$ and \\ Vivek Sharma BDS, MDS ${ }^{3}$
}

${ }^{1}$ Public Health Dentistry, ESI Dental College and Hospital, Sector 15, Guru Gobind Singh Indraprastha University, Rohini, Delhi, India, ${ }^{2}$ Prosthodontics, Faculty of Dentistry, Jamia Millia Islamia, Jamia Nagar, Delhi, India and ${ }^{3}$ Conservative Dentistry and Endodontics, ESIC Dental College, Guru Gobind Singh Indraprastha University, Rohini, Delhi, India

Author for correspondence: Sukhvinder Singh Oberoi, E-mail: drsukhvinder@gmail. com

Cite this article: Oberoi SS, et al. (2022). Saliva and its potential in coronavirus disease 2019 (COVID-19) cannot be ignored: A point of view. Infection Control \& Hospital Epidemiology, 43: 1284-1285, https://doi.org/10.1017/ice.2021.211
To the Editor-Recent research has shown that $\sim 1.2 \times 10^{8}$ infective copies/mL of severe acute respiratory coronavirus virus 2 (SARS$\mathrm{CoV}-2$ ) virus can be found in the salivary samples of coronavirus disease 2019 (COVID-19)-positive patients. ${ }^{1}$ The saliva and 
salivary glands have very high potential for the spread of the SARS$\mathrm{CoV}-2$ virus by virtue of its secretory nature and rich blood supply. The virus can even be transmitted through the saliva of the patients who are asymptomatic carriers. ${ }^{2}$

Research has demonstrated that ACE-2-positive cells and keratin epithelial cells of the salivary gland duct could be infected initially by the SARS-CoV virus, like the ACE-2-positive cells of the lung, indicating that the salivary gland's epithelial cells might be the source of infection after the entry of virus into the body. Therefore, during the early infection, the saliva can become an important source for the transmission of the virus. ${ }^{3}$

The mechanism involved in the entry of SARS-CoV-2 into the cells has demonstrated that it enters the human cells through ACE2 cell receptors. Thus, the salivary glands might also be a potential source for transmitting the SARS-CoV-2, which is important to consider. $^{4}$

Virus-infected droplets generated from the saliva can lead to the spread of the virus. ${ }^{2}$ Aerosols are liquid or solid particles $<5 \mu \mathrm{m}$ remain suspended in the air for long periods and evaporate faster and usually fall out. The larger droplets of $>5 \mu \mathrm{m}$ are heavier. They have the potential to fall out faster than they evaporate, and they do not remain suspended in the air for long. ${ }^{5}$

The aerosols carrying the virus penetrate the healthy human body and lungs via inhalation through nose or mouth. SARSCoV-2 can be transported $1 \mathrm{~m}$ during normal breathing, and the exhalation can lead to the diffusion of SARS-CoV-2 beyond $2 \mathrm{~m}$. Sneezing and coughing, or having contact with either mouth, nose, and eye mucosa, can lead to the rapid transmission of the disease in the society. ${ }^{5}$

Many previous studies have shown that dental clinics are a potential source of SARS-CoV-2 transmission. Dental treatment requires the use of ultrasonic scalers with slow-speed and high-speed hand pieces. These procedures produce and release aerosols and droplets ${ }^{6}$ that are pushed into the air for $\sim 1 \mathrm{~m}$ and then fall to the ground. Aerosols might be in the air for a very long time, which can lead to the dissemination of the virus and contaminate the environment of the dental clinic, further contributing to community transmission. ${ }^{7}$

The detection of throat and saliva samples via real-time reverse-transcriptase polymerase chain reaction (RT-PCR) has shown that the salivary count of SARS-CoV RNA was much more than the throat samples, supporting the idea of oral droplet transmission of SARS-CoV. Therefore, the virus can lead to the disease transmission via short as well as long-distance travel, putting the people who are in close and unprotected contact with SARS-CoV-2-infected patients at high risk. ${ }^{8}$

The characteristics of COVID-19 and dental procedures have posed unprecedented challenges for dental practitioners. The dental profession is involved with exposure to droplets and aerosols from saliva and other body fluids, so the chances of cross infection between dental practitioners and patients are very high. Every dental practitioner must fully understand the characteristics of COVID-19 and must strictly implement the most appropriate protective measures to reduce and control the risk of cross infection in dental procedures. Infection prevention and control practices during dental treatment are urgently needed.

Acknowledgments. I would like to thank Dr Nilima Sharma and Dr Vasudha Kak for their constant support and encouragement.

Financial support. No financial support was provided relevant to this article.

Conflicts of interest. All authors report no conflicts of interest relevant to this article.

\section{References}

1. To KK, Tsang OT, Yip CC, et al. Consistent detection of 2019 novel coronavirus in saliva. Clin Infect Dis 2020;71:841-843.

2. Yan J, Grantham M, Pantelic J, et al. Infectious virus in exhaled breath of symptomatic seasonal influenza cases from a college community. Proc Natl Acad Sci U S A 2018;115:1081-1086.

3. Liu L, Wei Q, Alvarez X, et al. Epithelial cells lining salivary gland ducts are early target cells of severe acute respiratory syndrome coronavirus infection in the upper respiratory tracts of rhesus macaques. J Virol 2011;85:4025-4030.

4. Wan Y, Shang J, Graham R, Baric RS, Li F. Receptor recognition by the novel coronavirus from Wuhan: an analysis based on decade-long structural studies of SARS coronavirus. J Virol 2020;94(7):e00127-20.

5. Moosavi MS, Aminishakib P, Ansari M. Antiviral mouthwashes: possible benefit for COVID-19 with evidence-based approach. J Oral Microbiol 2020;12(1):1794363.

6. Peng X, Xu X, Li Y, Cheng L, Zhou X, Ren B. Transmission routes of 2019nCoV and controls in dental practice. Int J Oral Sci 2020;12:9.

7. Li RW, Leung KW, Sun FC, Samaranayake LP. Severe acute respiratory syndrome (SARS) and the GDP. Part II: implications for GDPs. Br Dent $J$ 2004;197:130-134.

8. Li Y, Ren B, Peng X, et al. Saliva is a non-negligible factor in the spread of COVID-19. Mol Oral Microbiol 2020;35:141-145. 